\title{
Proteoglycan 4 (PRG4) expression and function \\ in dry eye associated inflammation
}

Nikhil G. Menon ${ }^{1}$, B.Sc., Ruchi Goyal ${ }^{1}$, M.S., Carolina Lema ${ }^{2}$, Ph.D., Paige S. Woods ${ }^{1}$, B.Sc., Gregory D. Jay ${ }^{3}$, M.D., PhD, Linda H. Shapiro ${ }^{4}$, Ph.D., Rachel L. Redfern ${ }^{2}$, Ph.D., Mallika Ghosh ${ }^{4}$, Ph.D., Tannin A. Schmidt ${ }^{1}$, Ph.D.

${ }^{1}$ Department of Biomedical Engineering Department, School of Dental Medicine, UConn Health, Farmington, CT, USA. ${ }^{2}$ The Ocular Surface Institute, College of Optometry, University of Houston, Houston, Texas, USA. ${ }^{3}$ Department of Emergency Medicine, Warren Alpert Medical School \& School of Engineering, Brown University, Providence, RI, USA. ${ }^{4}$ Department of Cell Biology, School of Medicine, UConn Health, Farmington, CT, USA.

Corresponding Author Address:

Dr. Tannin A. Schmidt

263 Farmington Ave, MC 17121

Biomedical Engineering Department

UConn Health

Farmington, CT, USA

06001

Tel: (860) 679-8361

Email: tschmidt@uchc.edu

Running Title: PRG4 in dry eye associated inflammation

Submitted to: BioArxiv 


\begin{abstract}
Purpose: Dry eye disease (DED) affects hundreds of millions worldwide. Proteoglycan 4 (PRG4) has been shown to improve signs and symptoms of DED in humans. The objectives of this study were to characterize endogenous PRG4 expression by telomerase-immortalized human corneal epithelial (hTCEpi) cells, examine how exogenous recombinant human PRG4 (rhPRG4) modulates cytokine and chemokine secretion in response to TNF $\alpha$ and IL-1 $\beta$, explore rhPRG4 as a potential substrate and/or inhibitor of MMP-9, and to understand how experimental dry (EDE) in mice affects PRG4 expression.
\end{abstract}

Methods: PRG4 secretion was quantified by Western blotting and PRG4 expression by immunocytochemistry. Cytokine/chemokine release was measured by ELISA, and MMP-9 inhibition was quantified using an MMP-9 inhibitor kit. EDE was induced in mice, and PRG4 was visualized by immunohistochemistry in the cornea and Western blotting in lacrimal gland lysate.

Results: hTCEpi cells synthesize and secrete PRG4 in vitro, which is inhibited by TNF $\alpha$ and IL$1 \beta$. TNF $\alpha$ and IL-1 $\beta$ significantly increased secretion of cytokine IL-6 and chemokines IL-8, IP10, RANTES, and ENA-78, and several of these chemokines were downregulated after cotreatment with rhPRG4. Fluorescently-labelled rhPRG4 was internalized by hTCEpi cells. rhPRG4 was not digested by MMP-9 and inhibited in vitro activity of exogenous MMP-9 both in solution and in the presence of human tears. Finally, EDE decreased corneal and lacrimal gland expression of PRG4.

Conclusions: These results demonstrate rhPRG4's anti-inflammatory properties in the corneal epithelium and its contribution to ocular surface homeostasis, furthering our understanding of PRG4's immunomodulatory properties in the context of DED inflammation. 
bioRxiv preprint doi: https://doi.org/10.1101/2020.10.01.318576; this version posted October 1, 2020. The copyright holder for this preprint (which was not certified by peer review) is the author/funder, who has granted bioRxiv a license to display the preprint in perpetuity. It is made available under aCC-BY-NC-ND 4.0 International license.

Key Words: Lubricin, PRG4, dry eye, inflammation, hTCEpi, corneal epithelial cells 


\section{Introduction}

Dry eye disease (DED) affects hundreds of millions of people worldwide, and effective treatment options are lacking. It is associated with significant pain, limitations in daily activities, diminished vitality, poor health in general, and often depression.[1-3]. DED is very prevalent, affecting $10-20 \%$ of the population in those aged between 20 and 40 years and more than $30 \%$ of those above 70 years [2]. While treatment options do exist for DED, treatment options are often misaligned with the fundamental mechanisms of the disease and do not fully address patient symptoms [4]. Indeed, a recent study demonstrated more than $60 \%$ of DED patients using either of the two FDA-approved drugs had discontinued treatment within 12 months , thus indicating effective treatment options are lacking [5].

Recently, topical administration of a full length recombinant human proteoglycan 4 (rhPRG4) was shown to be clinically effective in improving signs and symptoms of patients with DED [6]. This small, single site, clinical trial (NCT02507934) on 39 subjects with moderate DED assessed the safety and efficacy of rhPRG4 at $150 \mu \mathrm{g} / \mathrm{ml}$ as compared to a $0.18 \%$ sodium hyaluronate (HA) eye drop in subjects with moderate DED. The rhPRG4 solution demonstrated statistically significant effects compared to HA in: a) symptomatic improvements in foreign body sensation, sticky feeling, blurred vision, and photophobia in at least one eye b) improvement in objective signs of DED in corneal fluorescein staining, tear film break-up time, eyelid and conjunctival erythema, and daily mean instillations; and c) no treatment-related adverse events. However, there remains a significant need for basic science research on rhPRG4's biological properties and its potential therapeutic mechanisms of action in treating DED.

Tear film instability and tear hyper-osmolarity contribute to a positive feedforward loop in DED, leading to ocular surface damage and inflammation. Environmental stress, aging, bacterial 
infection, and contact lens wear can cause damage in the eye, specifically in the corneal epithelium and conjunctiva, which can lead to changes in tear film stability and osmolarity [7]. These changes can increase the production of pro-inflammatory cytokines, including interleukin (IL) $-1 \beta$ and tumor necrosis factor (TNF)- $\alpha$, from corneal epithelial cells, which further degrades the tear film and contributing to a vicious inflammatory cycle $[8,9]$. Elevated levels of IL-1 $\beta$, IL6 , and TNF $\alpha$ have also been reported in tears of patients with DED [10,11]. Changes in tear film stability and osmolarity also cause increased release of chemokines, including CCL5 (RANTES) [10,12], CXCL8 (IL-8) [11,13], and CXCL10 (IP-10), which attract immune cells to the corneal epithelium and further stimulate the proinflammatory cytokine production and matrix metalloproteinase (MMP) activity [7,8,12,13]. MMP-9 levels also increase in the tears of patients with DED, where they increase with DED severity, as well as in mice with experimental DED, and MMP-9 is used as a biomarker for DED [14-16]. Given the role inflammation plays in the pathogenesis of $\mathrm{DED}$, molecules that are able to appropriately modulate inflammatory activity in the cornea could lead to potential, more effective, future treatment options.

PRG4, also known as lubricin, is a mucin like glycoprotein that is present on the ocular surface where it plays a critical protective role in maintaining ocular surface integrity. PRG4 is present at the epithelial surface of human cornea and conjunctiva, where it helps maintain the tear film [17]. Lack of PRG4 in mice results in increased ocular surface damage $[18,19]$.

Mechanically, PRG4 functions as an ocular surface boundary lubricant, reducing friction at the interface between the eyelid, cornea, and contact lenses [20]. Full length rhPRG4 exhibits similar in vitro boundary lubricating properties to native PRG4, on both the ocular surface [19] and articular cartilage [21]. Biologically, recent studies in the context of synovial joint health and disease demonstrated that rhPRG4 has anti-inflammatory properties, including the ability to bind 
to and antagonize toll-like receptors, reducing inflammation by dampening nuclear factor kappa B (NFkB) activation and inflammatory cytokine expression [22], and the ability to inhibit fibroblast-like synoviocyte proliferation [23,24]. However, despite rhPRG4's promising potential as a treatment for DED, rhPRG4's anti-inflammatory properties and endogenous PRG4 expression in the context of ocular surface health and DED have yet to be examined.

The primary objectives of this study were therefore to characterize endogenous PRG4 expression by human corneal epithelial cells, and examine the ability of exogenous rhPRG4 to modulate cytokine and chemokine secretion in response to dry eye associated inflammatory stimuli, TNF $\alpha$ and IL-1 $\beta$, in human corneal epithelial cells. Secondary objectives were to explore rhPRG4 as a potential substrate and/or inhibitor of MMP-9, and determine if EDE modulates corneal and lacrimal gland PRG4 expression. 


\section{Methods}

\subsection{Human Corneal Epithelial Cell Culture}

\subsubsection{Expansion \& Differentiation:}

hTCEpi cells (kindly provided by Dr. James Jester) [25] were expanded with Keratinocyte Serum-Free Medium (KSFM) supplemented with $5 \mathrm{ng} / \mathrm{mL}$ epidermal growth factor (EGF) and $25 \mu \mathrm{g} / \mathrm{mL}$ bovine pituitary extract (BPE) (Gibco, Grand Island, NY) and seeded in 12 well plates. Each well received 100,000 cells in $2 \mathrm{~mL}$ of KSFM media. Cells were allowed to expand, to $80-90 \%$ confluency, for 48 hours. Cells in each well were then differentiated using DMEM/F12 (Gibco, Grand Island, NY) + 10\% FBS (R\&D Systems, Minneapolis, MN) + 10 ng/mL EGF (Gibco), as described previously [26].

\subsubsection{Inflammatory Stimuli \& rhPRG4 Treatment:}

After 4 days of differentiation, each well received $0.45 \mathrm{~mL}$ of stock rhPRG4 (Lubris Biopharma, Framingham, MA) or sterile PBS containing 0.01\% Tween-20 immediately followed by $1.55 \mathrm{~mL}$ of treatment media (DMEM/F12 + 12.9\% FBS + $12.9 \mathrm{ng} / \mathrm{mL}$ EGF). The treatment media was spiked with IL-1 $\beta$ (Peprotech, Cranbury, NJ), TNF $\alpha$ (Peprotech) or left alone as a control. The final concentrations were $10 \mathrm{ng} / \mathrm{mL}$ for IL- $1 \beta, 100 \mathrm{ng} / \mathrm{mL}$ for TNF $\alpha$, and 0 or 300 $\mu \mathrm{g} / \mathrm{mL}$ for rhPRG4. After 48 hours of treatment, the conditioned media was collected, aliquoted, and stored at $-20^{\circ} \mathrm{C}$. Each treatment was tested in triplicate in each experiment, and the experiment was performed three times $(\mathrm{N}=3)$.

\subsection{Western blot}


Sodium dodecyl sulphate-polyacrylamide gel electrophoresis (SDS-PAGE) was

performed with 3-8\% Tris-Acetate gels (Invitrogen, Carlsbad, CA), as described previously [27].

Briefly, samples (15 $\mu \mathrm{L}$ of conditioned media per well) were electrophoresed, followed by electroblotting to a PVDF membranes and blocked in 5\% non-fat dry milk (Biorad, Hercules, CA) in Tris-buffered saline $+0.05 \%$ Tween-20 (TBST) for $1 \mathrm{~h}$ at room temperature. Membranes were then probed with anti-PRG4 Ab LPN (1:1000, Invitrogen, PA3-118) in 3\% non-fat dry milk in TBST overnight at $4^{\circ} \mathrm{C}$. After washing with TBST, membranes were incubated with HRP conjugated anti-rabbit secondary antibody (1:2000, MilliporeSigma, Burlington, MA) for 1 hour and imaged on a G:Box Chemi XX9 imager (Syngene, Frederick, MD) using SuperSignal West Femto (Thermo Fisher Scientific, Waltham, MA). Resulting intensity of bands were quantified by densitometry with the Genetools (Syngene).

\subsection{ELISA analysis}

Conditioned media samples were analyzed using commercially available ELISAs as per manufacturer guidelines (BioLegend, San Diego, CA), at 2X and 8X dilutions for IL-6, IP-10, RANTES, and ENA-78, and at 8X and 32X dilution of IL-8. Resulting data was collected on a SpectraMax i3x plate reader (Molecular Devices, San Jose, CA), and concentrations were calculated using OD values within the standard curve range.

\subsection{Immunofluorescence Imaging}

hTCEpi cells were seeded at a density of 30,000 cells per well on sterile glass coverslips in 4-well dishes. Cells were differentiated and treated using FITC-tagged rhPRG4 as described above (2.2.2). After 2 days, conditioned media was collected, and cells were fixed with $0.5 \mathrm{~mL}$ 
of $4 \%$ paraformaldehyde for 20 minutes at room temperature, permeabilized with $0.5 \mathrm{~mL}$ of 0.1\% Triton X-100 in PBS for 5 minutes at room temperature, and blocked with 5\% normal goat serum (Rockland, Pottstown, PA) and 5\% BSA (MilliporeSigma) in PBS. Wells without FITCrhPRG4 were probed with anti PRG4 Ab LPN (1:500, Invitrogen) in blocking solution overnight at $4{ }^{\circ} \mathrm{C}$. The next day, wells were appropriately treated with anti-rabbit 594 antibody $(1: 1200$, MilliporeSigma) for 1 hour at room temperature and then DAPI (1:1000, Thermo Fisher Scientific) for 15 minutes at room temperature. The cover slips were then mounted with gold anti-fade mounting media (Thermo Fisher Scientific) and imaged on a Zeiss Axioskop2 microscope with an AxioCam digital camera (Zeiss, Oberkochen, Germany) using 63x oil objective. Slides with samples containing FITC-PRG4 were also imaged on a Zeiss LSM 880 confocal microscope with a $63 \mathrm{x}$ oil objective and a slice height of $0.36 \mu \mathrm{m}$.

\subsection{MMP-9 Digestion \& Inhibition}

First, rhPRG4 degradation from exogenous MMP-9 was assessed using gel electrophoresis and SimplyBlue protein stain. Briefly, rhPRG4 at $0.77 \mathrm{mg} / \mathrm{mL}$ was incubated with or without 9 $\mathrm{mU}$ of MMP-9 enzyme for 60 minutes at $37^{\circ} \mathrm{C}$. These samples were then electrophoresed on a 3$8 \%$ Tris-Acetate gel and stained with SimplyBlue, following manufacturer guidelines. Second, to assess the extent to which rhPRG4 inhibited in vitro MMP-9 activity, an MMP-9 inhibitor testing kit was used following manufacturer guidelines (Abcam, Cambridge, MA). This experiment was repeated using the same concentrations of rhPRG4 and MMP-9 in the presence of human tears. OD values were measured using an excitation wavelength of $328 \mathrm{~nm}$ and an emission wavelength of $420 \mathrm{~nm}$ on a SpectraMax i3x microplate reader. 


\subsection{Experimental Dry Eye Model}

\subsection{1: Sample Collection and Preparation:}

Mice with experimental dry eye (EDE) were obtained as previously described [28,29]. Briefly, 8 to 12-week old C57BL/6 mice (equal number male and female) were housed in a controlled room in which humidity was maintained at approximately $20 \%$ and temperature was maintained at $21^{\circ} \mathrm{C}$ to promote ocular surface desiccation. Additionally, mice were given subcutaneous scopolamine hydrobromide injections three times daily for five consecutive days to reduce tear production. After treatment, whole eyes were collected, snap frozen in optimal cutting temperature compound to obtain frozen tissue sections, and stored at $-80^{\circ} \mathrm{C}$ until PRG4 immunohistochemistry analysis. Lacrimal glands were also harvested and homogenized in $0.2 \%$ Triton X-100 (MilliporeSigma) containing a protease inhibitor cocktail (Roche) and prepared for PRG4 western blotting (2.2). Animal experiments were approved by the Institutional Animal Care and Use Committee at the University of Houston and adhered to the standards of the Association for Research in Vision and Ophthalmology Statement for the use of animals in ophthalmic and visual research.

\subsubsection{PRG4 Immunohistochemistry:}

Ten $\mu \mathrm{m}$ thick frozen eyeball sections were obtained on glass slides, fixed in cold acetone and then permeabilized with $0.1 \%$ Triton X-100/PBS. The sections were blocked with $15 \%$ goat serum (Abcam, Cambridge, United Kingdom) and then incubated overnight with anti-PRG4 Ab LPN primary antibody (Invitrogen) at $4^{\circ} \mathrm{C}$. The sections were then incubated for $1 \mathrm{~h}$ with Alexa Fluor 488 antibody (Abcam) and counterstained with DAPI. Images were captured by using the Delta Vision microscope (GE Healthcare, Chicago, IL). Fluorescence intensity was quantitated from captured images using ImageJ. 


\subsection{Statistical Analysis}

Data are expressed as the mean \pm SEM. The effect of inflammatory stimuli on endogenous PRG4 secretion by hTCEpi cells was assessed by one-way ANOVA followed by Dunnett's post hoc testing. The effect of inflammatory stimuli on cytokine and chemokine secretion by hTCEpi cells was also assessed by one-way ANOVA followed by Dunnett's post hoc testing. The effect of rhPRG4 treatment on cytokine and chemokine secretion within each inflammatory stimulus condition was assessed by one-tailed t-test. The effect of PRG4 on MMP9 activity was assessed by one-way ANOVA followed by Tukey post-hoc testing. The effect of

EDE on PRG4 localization in the cornea was assessed by one-tailed t-test. Finally, the effect of EDE on PRG4 expression in lacrimal gland lysate was assessed by one-tailed t-test. 


\section{Results}

\subsection{PRG4 secretion}

First, to determine endogenous secretion of PRG4 as well as any changes with the addition of inflammatory stimuli, conditioned media from cells treated for $48 \mathrm{~h}$ was collected and analysed using Western blotting. hTCEpi cells secreted PRG4 and this was reduced by treatment with inflammatory stimuli IL-1 $\beta$ and TNF $\alpha$. Conditioned media from hTCEpi cells contained PRG4, in both monomeric and dimeric form, as assessed by western blotting (Fig. 1A). The addition of either IL-1 $\beta$ or TNF $\alpha$ reduced levels of PRG4 secretion to $0.84 \pm 0.02(\mathrm{p}<0.05)$ and $0.82 \pm 0.06(\mathrm{p}<0.05)$ fold of control, respectively (Fig. 1B).

\subsection{Cytokine \& Chemokine Secretion}

To determine how cell secretion of cytokines and chemokines are influenced by inflammatory stimuli and rhPRG4, cells were treated with IL-1 $\beta$ or TNF $\alpha$ with or without the addition of rhPRG4 for $48 \mathrm{~h}$, and conditioned media was collected and analysed by ELISA. IL-1 $\beta$ and TNF $\alpha$ increased inflammatory cytokine and chemokine production by hTCEpi cells. TNF $\alpha$ significantly increased production by hTCEpi cells for all five cytokines and chemokines analysed: $15.02 \pm 6.56$-fold for IL-6 (from $1.32 \pm 0.33 \mathrm{ng} / \mathrm{mL}, \mathrm{p}<0.05$ ), $9.69 \pm 3.70$-fold for IL8 (from $23.29 \pm 10.40 \mathrm{ng} / \mathrm{mL}, \mathrm{p}<0.01$ ), $3.72 \pm 0.77$-fold for IP-10 (from $329.40 \pm 74.31 \mathrm{pg} / \mathrm{mL}$, $\mathrm{p}<0.01$ ), $3.9 \pm 1.18$-fold for RANTES (from $28.19 \pm 3.05 \mathrm{pg} / \mathrm{mL}, \mathrm{p}<0.001$ ), and $5.30 \pm 1.17$ fold for ENA-78 (from $44.80 \pm 18.14$ pg/mL, p < 0.001) (Fig. 2). IL-1 $\beta$ only provided a significant increase of 10.52 \pm 4.49-fold for ENA-78 (from 44.8 pg/mL, p < 0.05) (Fig. 2).

Treatment with rhPRG4 decreased production of several inflammatory cytokines/chemokines (Fig 2). In the absence of inflammatory stimuli, exogenous rhPRG4 
significantly reduced levels of IL-6 (to $0.70 \pm 0.08$-fold, $\mathrm{p}<0.01$ ), IL-8 (to $0.73 \pm 0.08$-fold, $\mathrm{p}<$ 0.05 ), and ENA-78 (to $0.37 \pm 0.17$-fold, $\mathrm{p}<0.05$ ) in the conditioned media. For samples treated with IL-1 $\beta$, exogenous rhPRG4 significantly reduced levels of RANTES (from $2.50 \pm 0.67$-fold to $1.20 \pm 0.47$-fold, $\mathrm{p}<0.05$ ) and ENA-78 (to $4.61 \pm 2.35$-fold, $\mathrm{p}<0.05$ ). For samples treated with TNF $\alpha$, exogenous rhPRG4 significantly reduced levels of IP-10 (to $3.72 \pm 0.77$-fold, $\mathrm{p}<$ 0.05), RANTES (to $1.65 \pm 0.57$-fold, $\mathrm{p}<0.01$ ), and ENA-78 (to $1.15 \pm 0.31$-fold, $\mathrm{p}<0.001$ ).

\subsection{PRG4 Visualization and Internalization}

To visualize endogenous PRG4 expression and exogenous rhPRG4 internalization under normal and inflammatory conditions, hTCEpi cells were seeded onto glass coverslips and received IL-1 $\beta$ or TNF $\alpha$ with or without FITC-tagged rhPRG4 for $48 \mathrm{~h}$. Endogenous expression and rhPRG4 internalization was assessed by immunofluorescence and confocal microscopy, respectively. hTCEpi cells expressed PRG4 endogenously and were able to internalize exogenous rhPRG4 in response to inflammatory stimuli. Endogenous PRG4 was immunolocalized within and at the cell surface of hTCEpi cells both with and without the addition of inflammatory stimuli (Fig. 3A-C). Confocal imaging demonstrated slices within the cell contained exogenous FITC-tagged rhPRG4 as punctate staining (supplemental data), confirming that it can be internalized by hTCEpi cells in both control and IL-1 $\beta$ stimulation (Fig 3D-F). Interestingly, TNF $\alpha$ stimulation led to internalization of PRG4 expression with apparent loss of surface staining.

\subsection{Inhibition of MMP-9 activity by PRG4}


rhPRG4 is not degraded by MMP-9, and in vitro activity of exogenous MMP-9 was inhibited by rhPRG4 both in solution and in the presence of human tear. No evidence of rhPRG4 in vitro degradation by exogenous MMP-9 was observed using gel electrophoresis and protein staining after co-incubation for $1 \mathrm{~h}$ at $37^{\circ} \mathrm{C}$ (Fig. 4A). Analysis with an in vitro MMP-9 specific inhibitor assay demonstrated that rhPRG4 reduced in vitro activity of exogenous MMP-9 to $23 \% \pm 11 \%$ for $150 \mu \mathrm{g} / \mathrm{mL}$ ( $\mathrm{p}<0.001), 16.5 \% \pm 8.2 \%$ for $300 \mu \mathrm{g} / \mathrm{mL}$ ( $\mathrm{p}<0.001$ ), and $5.3 \% \pm 2.6 \%$ for 450 $\mu \mathrm{g} / \mathrm{mL}$ ( $\mathrm{p}<0.001$, Fig. 4B) compared to no rhPRG4 control. rhPRG4 also reduced in vitro activity of exogenous MMP-9 in the presence of human tears, (Fig. 4C) to $80.9 \% \pm 6.6 \%$ for 150 $\mu \mathrm{g} / \mathrm{mL}(\mathrm{p}>0.05), 41.1 \% \pm 7.6 \%$ for $300 \mu \mathrm{g} / \mathrm{mL}(\mathrm{p}<0.001)$, and $15.6 \% \pm 5.7 \%$ for $450 \mu \mathrm{g} / \mathrm{mL}$ ( $p<0.001$, Fig. 4B) compared to no rhPRG4 control. Additionally, there was a dose-dependent effect in reducing exogenous MMP-9 activity in the presence of tears $(p<0.001-p<0.05)$.

\subsection{Experimental dry eye model}

To evaluate changes in PRG4 expression in an EDE model, mouse corneas from untreated and EDE mice were evaluated by IHC and lacrimal gland lysate samples were assayed by Western blotting. PRG4 expression was significantly reduced in both the cornea and lacrimal gland in EDE. PRG4 immunolocalization was clear in the cornea epithelium of untreated mice

(Fig. 5A) and was reduced in the corneas of mice with EDE (Fig. 5B); there was a 2.96-fold reduction in the mean pixel intensity of PRG4 immunostaining between corneas of untreated mice and mice with EDE (Fig. 5C, p < 0.01). Lacrimal gland lysate from mice with EDE had reduced PRG4 production of $0.40 \pm 0.24$-fold compared to lysate from untreated mice (Fig. 5D$\mathbf{E}, \mathrm{p}<0.05)$. 


\section{Discussion}

The in vivo results of this study demonstrated for the first time that ocular surface PRG4 can be diminished in an experimental model of DED. In this model, which results in ocular surface damage and reduced tear production [28], PRG4 immunolocalization was reduced at the corneal epithelium, and PRG4 expression in lacrimal gland cell lysate was reduced. While unchallenged PRG4-deficient mice were previously shown to have increased ocular surface damage [18], the current data establish a relationship between DED and diminished PRG4 expression at the ocular surface. Given the critical role PRG4 seems to play in maintaining homeostasis, the reduction of PRG4 may be a core mechanism in the progression of DED, leading directly to increased evaporation, increased friction, and a pro-inflammatory environment. The epithelial glycocalyx, of which PRG4 is likely an integral part, is similarly involved in the retention of water at the ocular surface as the lipid layer. The data herein suggest that the loss of PRG4 expression in the corneal epithelia is at least a co-equal aspect of the positive feedback loop of disease pathogenesis in DED.

In addition, the in vitro results presented here extend previous studies examining PRG4 on the ocular surface as well as the regulation of PRG4 expression by other cell types. While PRG4 has previously been immunolocalized in human corneal epithelium [18], the results here demonstrate that PRG4 is expressed and secreted by hTCEpi cells and is downregulated by IL-1 $\beta$ and TNF $\alpha$. This is also consistent with previous studies examining PRG4 secretion in synoviocytes [23], in chondrocytes with cartilage explants [30], and in synovial fluid after unilateral anterior cruciate ligament injury, where an increase in the concentration of inflammatory cytokines, including IL- $1 \beta$ and TNF $\alpha$ was associated with a reduction of PRG4 
[31]. Given the parallels with other organ systems, these data suggest the addition of exogenous rhPRG4 may contribute to restoring homeostatic biological conditions [21,23,24,32,33].

A key finding of this study is that exogenous rhPRG4 can inhibit hTCEpi production of several chemokines stimulated by proinflammatory signals. Specifically, rhPRG4 treatment inhibited the RANTES, IP-10, and ENA-78 response to IL-1 $\beta$ or TNF $\alpha$ (Fig. 2). RANTES is known to play a key role in promoting lymphocyte migration to the corneal epithelium [34] and is upregulated in the tears of patients with DED [14]. IP-10 is a chemoattractant for Th1 lymphocytes and monocytes [35], and it is also upregulated in the tears of patients with DED [14]. ENA-78, which is involved in neutrophil activation and chemotaxis [36], is another chemokine found to be upregulated in the tears of patients with DED [37], and it has not been extensively studied in the corneal epithelium. While PRG4 purified from synovial fluid was previously shown to have anti-inflammatory effects in an induced-DED blinking eye model, where it reduced secretion of IL-1 $\beta, \mathrm{TNF} \alpha$, and IL-8 [38], the present study demonstrates rhPRG4 has an in vitro anti-inflammatory effect on chemokines and long range signals to a variety of immune cell classes. Accordingly, the anti-inflammatory effect of PRG4 may stem from its ability to normalize the microenvironment through simultaneous friction reduction, downregulation of proinflammatory cytokines, and reduction of the recruitment of new immune cells. This pleiotropic nature of the molecule is unique, and strongly motivates its use for, and study in, DED, where multiple coincident etiologies are commonly observed.

Another key finding of this work is the visualization of exogenous FITC-labelled rhPRG4 being internalized by hTCEpi cells (Fig. 3). Both in basal conditions and with the addition of inflammatory stimuli, exogenous rhPRG4 was internalized and localized inside the cell, as visualized through confocal microscopy (Fig. 3), suggesting coupling of the molecule to 
intracellular signaling pathways, as seen in macrophages previously [39]. Given that rhPRG4 can modulate NFkB activity in other systems [24,38], future studies could also examine the effect of rhPRG4 on NFkB signaling, or other signaling pathways, as a potential mechanism by which rhPRG4 exerts its anti-inflammatory properties on corneal epithelial cells. Interestingly, and qualitatively, there appeared to be an increase in internalization with the addition of TNF $\alpha$. Future work examining colocalization of rhPRG4 with endosomal markers will provide important clues to the fate of rhPRG4 post internalization. It is also worth noting rhPRG4 tagged with FITC also retained its ability to reduce levels of cytokine and chemokine secretion from hTCEpi cells (data not shown). This suggests that rhPRG4's biological activity, at least in the context studied here, was not negatively affected by fluorescent tagging and therefore FITCtagged rhPRG4 could be a useful reagent in the future to explore PRG4's internalization into cells as well as its biological mechanism of action. rhPRG4 has been previously shown to be internalized in macrophages mediated, in part, through interactions with CD44 [39]. However, the precise processes by which PRG4 is internalized in hTCEpi cells (i.e. through receptor interactions, endocytosis, or a combination of the two) and the role it plays in rhPRG4's antiinflammatory mechanism of action remain under study.

Initial in vitro analysis here demonstrated that rhPRG4 is not a proteolytic substrate of MMP-9 (Fig. 4). While PRG4 is a substrate of other enzymes, including cathepsin S [40], cathepsin G [41], MMP-1 [42], and MMP-7 [42], it is not subject to degradation by MMP-9. The data also indicate that rhPRG4 inhibits in vitro activity of exogenous MMP-9 (Fig 4). Other studies have demonstrated that exogenous purified PRG4 can decrease MMP-9 levels in tears from a DED cell model [38] and MMP-9 gene expression stimulated by IL-1 $\beta$ in synoviocytes [23]. However, the inhibition of MMP-9 activity observed here is an important and potentially 
significant discovery. This inhibition effect was observed in solution and in the presence of human tears in a dose dependent manner. rhPRG4 may be inhibiting MMP-9 activity through the binding of the hemopexin-like (PEX) domain present on both rhPRG4 and MMP-9 [43,44]. The MMP-9 PEX domain binds to CD44, gelatin and a4ß1 integrins, and its inhibition may prevent homodimerization and reduce additional inflammatory signaling, including through MMP-9 damage-associated molecular pattern related pathways, such as Myd88 and TLR4, which are strongly associated with DED severity [28,45] Given the role MMP-9 plays in the pathogenesis of DED, these data may help elucidate some of the clinical efficacy of PRG4 in treating DED

\section{Conclusion}

In conclusion, these results underpin the understanding of PRG4 expression and antiinflammatory properties of rhPRG4 within the context of corneal epithelium in DED. The demonstrated clinical utility of rhPRG4 in improving signs and symptoms in a small single site clinical trial, combined with ongoing research studying rhPRG4's anti-inflammatory properties in other systems $[32,39,46,47]$ reveals a therapeutic mechanism of action. Collectively these findings provide the foundation and motivation for continued basic research in further understanding PRG4's properties on the ocular surface, both in vitro and in vivo, as well as expanding clinical evaluation of its ability to effectively provide relief to those who suffer from DED. 


\section{Acknowledgments}

We also gratefully acknowledge Dr. David Sullivan and Wendy Kam (Schepens Eye

Research Institute, Boston MA) for aid with the culture of the hTCEpi as well as Dr. James

Jester (University of California Irvine) for providing the cells. Finally, we thank Dr. Benjamin D.

Sullivan (TearLab Corp) for discussions on and critique of the manuscript.

\section{Financial Support}

This work was supported by the Department of Biomedical Engineering at UConn Health (TAS), National Institute of Health [grant numbers R01HL127449 (LHS and MG) and R01AR067748 (GDJ)], and National Institutes of Health [grant numbers EY023628 (RLR), EY07551 (Laura Frishman)]. No funding source was involved in the collection, analysis, interpretation of data, or writing this report.

\section{Conflict of Interest}

TAS and GDJ have authored patents on rhPRG4 and hold equity in Lubris LLC, MA, USA. TAS is also a paid consultant for Lubris LLC, MA, USA. All other authors have nothing to disclose. 


\section{References}

[1] Smith JA, Albenz J, Begley C, Caffery B, Nichols K, Schaumberg D, et al. The epidemiology of dry eye disease: Report of the epidemiology subcommittee of the international Dry Eye WorkShop (2007). Ocul Surf 2007;5:93-107. https://doi.org/10.1016/s1542-0124(12)70082-4.

[2] Stapleton F, Alves M, Bunya VY, Jalbert I, Lekhanont K, Malet F, et al. TFOS DEWS II Epidemiology Report. Ocul Surf 2017;15:334-65. https://doi.org/10.1016/j.jtos.2017.05.003.

[3] Miljanović B, Dana R, Sullivan DA, Schaumberg DA. Impact of Dry Eye Syndrome on Vision-Related Quality of Life. Am J Ophthalmol 2007;143. https://doi.org/10.1016/j.ajo.2006.11.060.

[4] Holland EJ, Darvish M, Nichols KK, Jones L, Karpecki PM. Efficacy of topical ophthalmic drugs in the treatment of dry eye disease: A systematic literature review. Ocul Surf 2019;17:412-23. https://doi.org/10.1016/j.jtos.2019.02.012.

[5] White DE, Zhao Y, Ogundele A, Fulcher N, Acs A, Moore-Schiltz L, et al. Real-world treatment patterns of cyclosporine ophthalmic emulsion and lifitegrast ophthalmic solution among patients with dry eye. Clin Ophthalmol 2019;13:2285-92. https://doi.org/10.2147/OPTH.S226168.

[6] Lambiase A, Sullivan BD, Schmidt TA, Sullivan DA, Jay GD, Truitt ER, et al. A TwoWeek, Randomized, Double-masked Study to Evaluate Safety and Efficacy of Lubricin (150 $\mu \mathrm{g} / \mathrm{mL}$ ) Eye Drops Versus Sodium Hyaluronate (HA) 0.18\% Eye Drops (Vismed®) in Patients with Moderate Dry Eye Disease. Ocul Surf 2017;15:77-87. https://doi.org/10.1016/j.jtos.2016.08.004.

[7] Stevenson W, Chauhan SK, Dana R. Dry eye disease: An immune-mediated ocular surface disorder. Arch Ophthalmol 2012;130:90-100.

https://doi.org/10.1001/archophthalmol.2011.364.

[8] Stern ME, Pflugfelder SC. Inflammation in dry eye. Ocul Surf 2004;2:124-30. https://doi.org/10.1016/S1542-0124(12)70148-9.

[9] Massingale ML, Li X, Vallabhajosyula M, Chen D, Wei Y, Asbell PA. Analysis of inflammatory cytokines in the tears of dry eye patients. Cornea 2009;28:1023-7. https://doi.org/10.1097/ICO.0b013e3181a16578.

[10] Lam H, Bleiden L, de Paiva CS, Farley W, Stern ME, Pflugfelder SC. Tear Cytokine Profiles in Dysfunctional Tear Syndrome. Am J Ophthalmol 2009;147:198-205.e1. https://doi.org/10.1016/j.ajo.2008.08.032.

[11] Pflugfelder SC, Jones D, Ji Z, Afonso A, Monroy D. Altered cytokine balance in the tear fluid and conjunctiva of patients with Sjogren's syndrome keratoconjunctivitis sicca. Curr Eye Res 1999;19:201-11. https://doi.org/10.1076/ceyr.19.3.201.5309. 
[12] El-Annan J, Goyal S, Zhang Q, Freeman GJ, Sharpe AH, Dana R. Regulation of T-cell chemotaxis by programmed Death-Ligand 1 (PD-L1) in dry eye-associated corneal inflammation. Investig Ophthalmol Vis Sci 2010;51:3418-23. https://doi.org/10.1167/iovs.09-3684.

[13] Enríquez-de-Salamanca A, Castellanos E, Stern ME, Fernández I, Carreño E, GarcíaVázquez C, et al. Tear cytokine and chemokine analysis and clinical correlations in evaporative-type dry eye disease. Mol Vis 2010;16:862-73.

[14] Pinto-fraga J, Enríquez-de-salamanca A, Calonge M, González-garcía MJ, López-miguel A, López-de A, et al. The Ocular Surface Severity, therapeutic , and activity tear biomarkers in dry eye disease $\square$ : An analysis from a phase III clinical trial ?. Ocul Surf 2018;16:368-76. https://doi.org/10.1016/j.jtos.2018.05.001.

[15] Kaufman HE. The practical detection of MMP-9 diagnoses ocular surface disease and may help prevent its complications. Cornea 2013;32:211-6. https://doi.org/10.1097/ICO.0b013e3182541e9a.

[16] Luo L, Li DQ, Doshi A, Farley W, Corrales RM, Pflugfelder SC. Experimental dry eye stimulates production of inflammatory cytokines and MMP-9 and activates MAPK signaling pathways on the ocular surface. Investig Ophthalmol Vis Sci 2004;45:4293-301. https://doi.org/10.1167/iovs.03-1145.

[17] Rabiah NI, Sato Y, Kannan A, Kress W, Straube F, Fuller GG. Understanding the adsorption and potential tear film stability properties of recombinant human lubricin and bovine submaxillary mucins in an in vitro tear film model. Colloids Surfaces B Biointerfaces 2020;195:111257. https://doi.org/10.1016/j.colsurfb.2020.111257.

[18] Schmidt TA, Sullivan DA, Knop E, Richards SM, Knop N, Liu S, et al. Transcription, translation, and function of lubricin, a boundary lubricant, at the ocular surface. JAMA Ophthalmol 2013;131:766-76. https://doi.org/10.1001/jamaophthalmol.2013.2385.

[19] Samsom ML, Morrison S, Masala N, Sullivan BD, Sullivan DA, Sheardown H, et al. Characterization of full-length recombinant human Proteoglycan 4 as an ocular surface boundary lubricant. Exp Eye Res 2014;127:14-9. https://doi.org/10.1016/j.exer.2014.06.015.

[20] Samsom M, Chan A, Iwabuchi Y, Subbaraman L, Jones L, Schmidt TA. In vitro friction testing of contact lenses and human ocular tissues: Effect of proteoglycan 4 (PRG4). Tribol Int 2015;89:27-33. https://doi.org/10.1016/j.triboint.2014.11.022.

[21] Abubacker S, Dorosz SG, Ponjevic D, Jay GD, Matyas JR, Schmidt TA. Full-Length Recombinant Human Proteoglycan 4 Interacts with Hyaluronan to Provide Cartilage Boundary Lubrication. Ann Biomed Eng 2016;44:1128-37. https://doi.org/10.1007/s10439-015-1390-8.

[22] Alquraini A, Garguilo S, Souza GD, Zhang LX, Schmidt TA, Jay GD, et al. The interaction of lubricin / proteoglycan 4 ( PRG4 ) with toll-like receptors 2 and 4 $\square$ : an anti- 
inflammatory role of PRG4 in synovial fluid. Arthritis Res Ther 2015:1-12. https://doi.org/10.1186/s13075-015-0877-x.

[23] Alquraini A, Jamal M, Zhang L, Schmidt T, Jay GD, Elsaid KA. The autocrine role of proteoglycan-4 (PRG4) in modulating osteoarthritic synoviocyte proliferation and expression of matrix degrading enzymes. Arthritis Res Ther 2017;19:1-15. https://doi.org/10.1186/s13075-017-1301-5.

[24] Al-Sharif A, Jamal M, Zhang LX, Larson K, Schmidt TA, Jay GD, et al. Lubricin/Proteoglycan 4 Binding to CD44 Receptor: A Mechanism of the Suppression of Proinflammatory Cytokine-Induced Synoviocyte Proliferation by Lubricin. Arthritis Rheumatol (Hoboken, NJ) 2015;67:1503-13. https://doi.org/10.1002/art.39087.

[25] Robertson DM, Li L, Fisher S, Pearce VP, Shay JW, Wright WE, et al. Characterization of growth and differentiation in a telomerase-immortalized human corneal epithelial cell line. Investig Ophthalmol Vis Sci 2005;46:470-8. https://doi.org/10.1167/iovs.04-0528.

[26] Ding J, Wirostko B, Sullivan DA. Human growth hormone promotes corneal epithelial cell migration in vitro. Cornea 2015;34:686-92. https://doi.org/10.1097/ICO.0000000000000418.

[27] Steele BL, Alvarez-Veronesi MC, Schmidt TA. Molecular weight characterization of PRG4 proteins using multi-angle laser light scattering (MALLS). Osteoarthr Cartil 2013;21:498-504. https://doi.org/10.1016/j.joca.2012.12.002.

[28] Reins RY, Lema C, Courson J, Kunnen CME, Redfern RL. MyD88 deficiency protects against dry eye-induced damage. Investig Ophthalmol Vis Sci 2018;59:2967-76. https://doi.org/10.1167/iovs.17-23397.

[29] Lema C, Reins RY, Redfern RL. High-mobility group box 1 in dry eye inflammation. Investig Ophthalmol Vis Sci 2018;59:1741-50. https://doi.org/10.1167/iovs.17-23363.

[30] Schmidt TA, Gastelum NS, Han EH, Nugent-Derfus GE, Schumacher BL, Sah RL. Differential regulation of proteoglycan 4 metabolism in cartilage by IL-1 $\alpha$, IGF-I, and TGF- $\beta 1$. Osteoarthr Cartil 2008;16:90-7. https://doi.org/https://doi.org/10.1016/j.joca.2007.05.009.

[31] Elsaid KA, Fleming BC, Oksendahl HL, Machan JT, Fadale PD, Hulstyn MJ, et al. Decreased lubricin concentrations and markers of joint inflammation in the synovial fluid of patients with anterior cruciate ligament injury. Arthritis Rheum 2008;58:1707-15. https://doi.org/10.1002/art.23495.

[32] Iqbal SM, Leonard C, Regmi SC, De Rantere D, Tailor P, Ren G, et al. Lubricin/Proteoglycan 4 binds to and regulates the activity of Toll-Like Receptors in Vitro. Sci Rep 2016;6:1-12. https://doi.org/10.1038/srep18910.

[33] Ludwig TE, McAllister JR, Lun V, Wiley JP, Schmidt TA. Diminished cartilagelubricating ability of human osteoarthritic synovial fluid deficient in proteoglycan 4 : 
Restoration through proteoglycan 4 supplementation. Arthritis Rheum 2012;64:3963-71. https://doi.org/10.1002/art.34674.

[34] Stern ME, Gao J, Siemasko KF, Beuerman RW, Pflugfelder SC. The role of the lacrimal functional unit in the pathophysiology of dry eye 2004;78:409-16.

https://doi.org/10.1016/j.exer.2003.09.003.

[35] Taub DD, Lloyd AR, Conlon K, Wang JM, Ortaldo JR, Harada A, et al. Recombinant human interferon-inducible protein 10 is a chemoattractant for human monocytes and $\mathrm{T}$ lymphocytes and promotes T cell adhesion to endothelial cells. J Exp Med 1993;177:1809-14. https://doi.org/10.1084/jem.177.6.1809.

[36] Walz BA, Burgener R, Car B, Baggiolini M, Kunkel SL, Strieter RM. Structure and Neutrophil-activating Properties of a Novel Inflammatory Peptide (ENA-78) with Homology to Interleukin 8. J Exp Med 1991;174.

[37] Na K, Mok J, Kim JY, Rho CR, Joo C. Soluble Receptors and Clinical Severity of Dry Eye Disease 2012;53:1-4. https://doi.org/10.1167/iovs.11-9417.

[38] Seo J, Byun WY, Alisafaei F, Georgescu A, Yi Y-S, Massaro-Giordano M, et al. Multiscale reverse engineering of the human ocular surface. Nat Med 2019;25:1310-8. https://doi.org/10.1038/s41591-019-0531-2.

[39] Qadri M, Jay GD, Zhang LX, Wong W, Reginato AM, Sun C, et al. Recombinant human proteoglycan-4 reduces phagocytosis of urate crystals and downstream nuclear factor kappa B and inflammasome activation and production of cytokines and chemokines in human and murine macrophages. Arthritis Res Ther 2018;20:1-16. https://doi.org/10.1186/s13075-018-1693-x.

[40] Regmi SC, Samsom ML, Heynen ML, Jay GD, Sullivan BD, Srinivasan S, et al. Degradation of proteoglycan 4/lubricin by cathepsin S: Potential mechanism for diminished ocular surface lubrication in Sjögren's syndrome. Exp Eye Res 2017;161:1-9. https://doi.org/10.1016/j.exer.2017.05.006.

[41] Huang S, Thomsson KA, Jin C, Alweddi S, Struglics A, Rolfson O, et al. Cathepsin g Degrades Both Glycosylated and Unglycosylated Regions of Lubricin, a Synovial Mucin. Sci Rep 2020;10:1-12. https://doi.org/10.1038/s41598-020-61161-5.

[42] Jones A, Hughes C, Wainright S, Flannery C, Little C, Caterson B, et al. Degradation of Prg4 / Szp By Matrix Proteases. 49th Annu Meet Orthop Res Soc Pap \# 0133 2003:133.

[43] Roeb E, Schleinkofer K, Kernebeck T, Pötsch S, Jansen B, Behrmann I, et al. The matrix metalloproteinase 9 (MMP-9) hemopexin domain is a novel gelatin binding domain and acts as an antagonist. J Biol Chem 2002;277:50326-32. https://doi.org/10.1074/jbc.M207446200.

[44] Piccard H, Van den Steen PE, Opdenakker G. Hemopexin domains as multifunctional liganding modules in matrix metalloproteinases and other proteins. J Leukoc Biol 
2007;81:870-92. https://doi.org/10.1189/jlb.1006629.

[45] Redfern RL, Barabino S, Baxter J, Lema C, McDermott AM. Dry eye modulates the expression of toll-like receptors on the ocular surface. Exp Eye Res 2015;134:80-9. https://doi.org/10.1016/j.exer.2015.03.018.

[46] Sarkar A, Chanda A, Regmi SC, Karve K, Deng L, Jay GD, et al. Recombinant human PRG4 (rhPRG4) suppresses breast cancer cell invasion by inhibiting TGF $\beta$-HyaluronanCD44 signalling pathway. PLoS One 2019;14:1-29.

https://doi.org/10.1371/journal.pone.0219697.

[47] Das N, Schmidt TA, Krawetz RJ, Dufour A. Proteoglycan 4: From Mere Lubricant to Regulator of Tissue Homeostasis and Inflammation: Does proteoglycan 4 have the ability to buffer the inflammatory response? BioEssays 2019;41:1-9.

https://doi.org/10.1002/bies.201800166. 


\section{Figure Legends}

Figure 1. Effect of inflammatory stimuli on PRG4 secretion in hTCEpi cells. Western blot analysis of conditioned media samples from control, $100 \mathrm{ng} / \mathrm{mL} \mathrm{TNF} \alpha$, or $10 \mathrm{ng} / \mathrm{mL} \mathrm{IL}-1 \beta$ conditions with anti-PRG4 Ab (A) densitometry of relative secretion compared to control (B). * $=\mathrm{p}<0.05$. Data are mean $\pm \operatorname{SEM}(\mathrm{n}=4)$

Figure 2. Effect of rhPRG4 on proinflammatory cytokine and chemokine secretion with inflammatory stimuli. Relative fold change in production of IL-6 (A), IL-8, (B), IP-10 (C), RANTES (D), ENA-78 (E) by differentiated hTCEpi cells treated with $100 \mathrm{ng} / \mathrm{mL}$ TNF $\alpha$ or 10 $\mathrm{ng} / \mathrm{mL}$ IL-1 $\beta$ with or without $300 \mu \mathrm{g} / \mathrm{mL}$ of $\operatorname{rhPRG} 4$, measured by ELISA, $*=\mathrm{p}<.05, * *=\mathrm{p}<$ $.01, * * *=p<.001$. Data are mean \pm SEM $(n=10)$

Figure 3. Effect of inflammatory stimuli on endogenous and exogenous PRG4 immunolocalization. Immunolocalization of PRG4 in hTCEpi cells with anti-PRG4 Ab LPN (A), and those treated with $10 \mathrm{ng} / \mathrm{ml} \mathrm{IL-1 \beta}$ (B) or $100 \mathrm{ng} / \mathrm{ml} \mathrm{TNF} \alpha(\mathrm{C})$. Confocal microscopy visualization of hTCEpi cells treated with FITC-tagged PRG4 (D), along with IL-1 $\beta(\mathrm{E})$, or $\mathrm{TNF} \alpha(\mathrm{F})$. Nuclei are stained with DAPI. Scale bar is $10 \mu \mathrm{m}, 63 \mathrm{X}$ magnification for A-C, 63X (x2) magnification for D-F.

Figure 4. Effect of rhPRG4 on exogenous MMP9 activity in vitro. rhPRG4 incubated with or without MMP9 for 60 minutes at 37C (A). Exogenous MMP9 activity with $150 \mathrm{ug} / \mathrm{mL}, 300$ $\mathrm{ug} / \mathrm{mL}$, and $450 \mathrm{ug} / \mathrm{mL}$ of rhPRG4 in solution (B) or in the presence of normal human tears (C). $*=\mathrm{p}<.05, * * *=\mathrm{p}<.001$. Data are mean $\pm \operatorname{SEM}(\mathrm{n}=6)$

Figure 5. Effect of experimental dry eye (EDE) on PRG4 expression in the cornea and the lacrimal gland in vivo. PRG4 in mouse cornea immunolocalized with anti-PRG4 Ab LPN from untreated mice (A) and mice with $\operatorname{EDE}(\mathrm{B})$, quantified using ImageJ, $*=\mathrm{p}<.05, \mathrm{n}=4(\mathrm{C})$. Lacrimal gland lysate analyzed by western blot using anti-PRG4 Ab LPN as primary antibody 
(D), Densitometry of relative fold change in PRG4 (E). ** $=\mathrm{p}<.01$, Data are mean \pm SEM $(\mathrm{n}=$

Supplemental Figure: hTCEpi cells treated with FITC-tagged PRG4 and no stimulus (A), IL-1 $\beta$

(B) or TNF $\alpha(C)$. Nuclei are stained with DAPI. Scale bar is $10 \mu \mathrm{m}, 126 \mathrm{X}$ magnification 


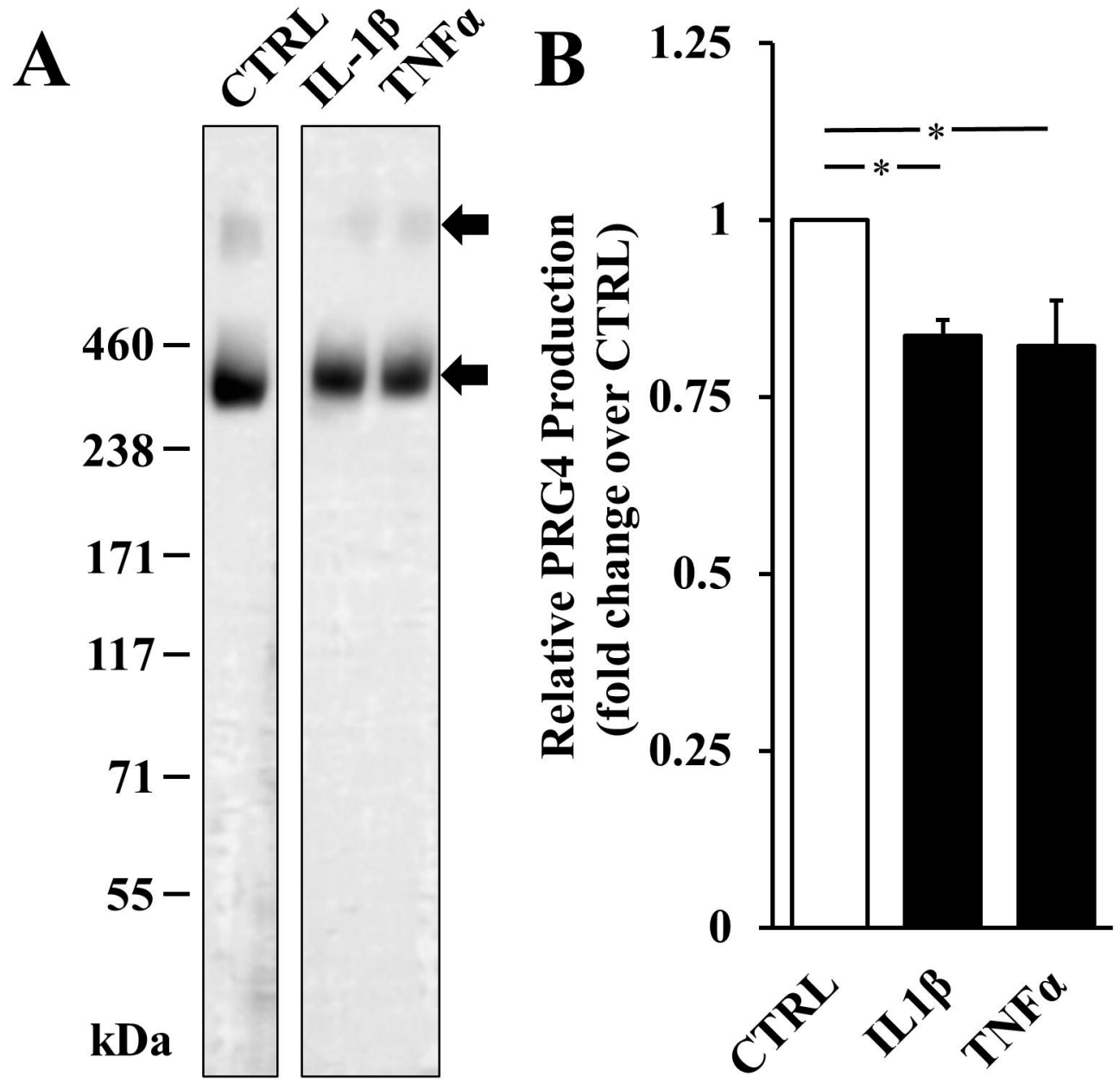




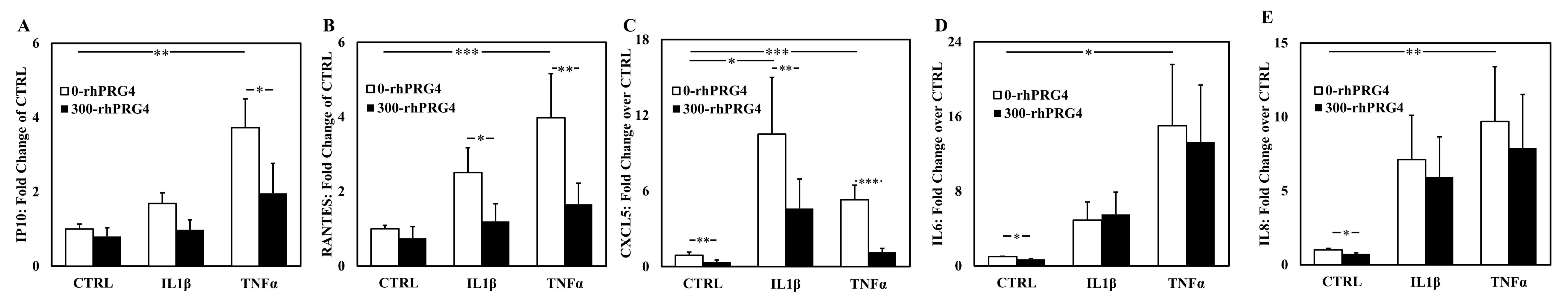




\section{Control}

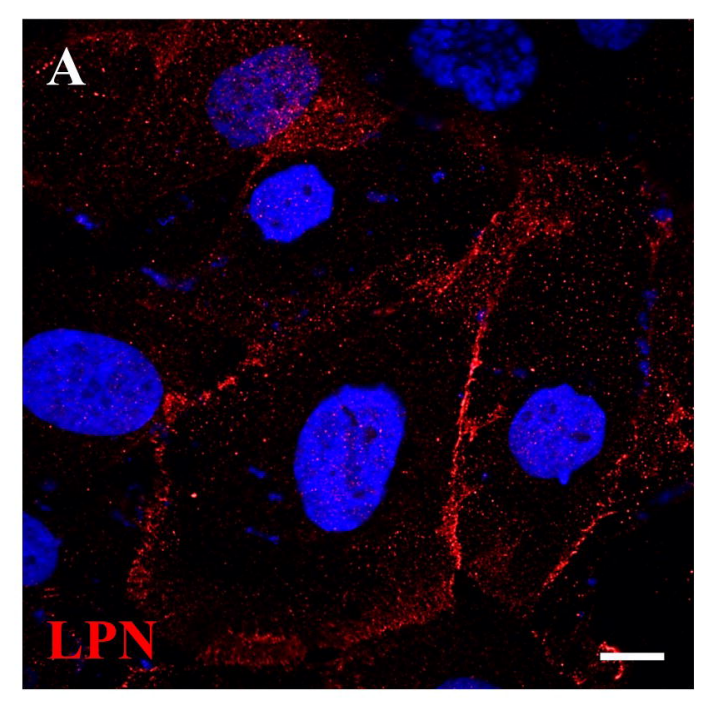

D

Exogenous PRG4 (FITC-rhPRG4)

(LPN)
Endogenous PRG4
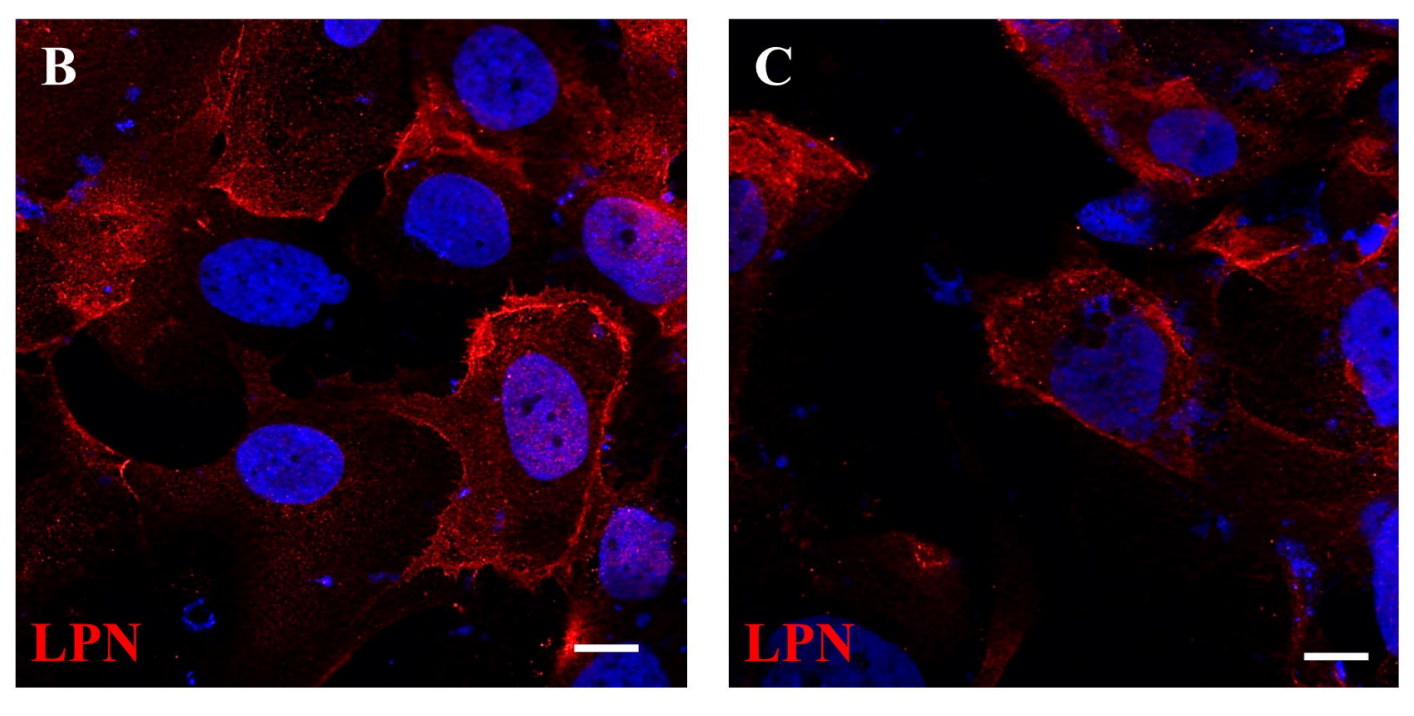

F

FITC-rhPRG4 
A rhPRG4 +

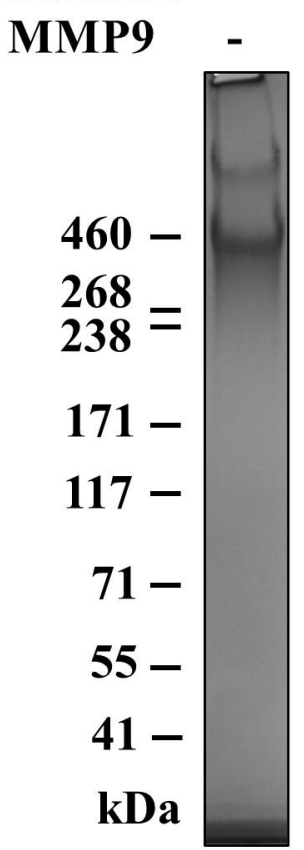

B
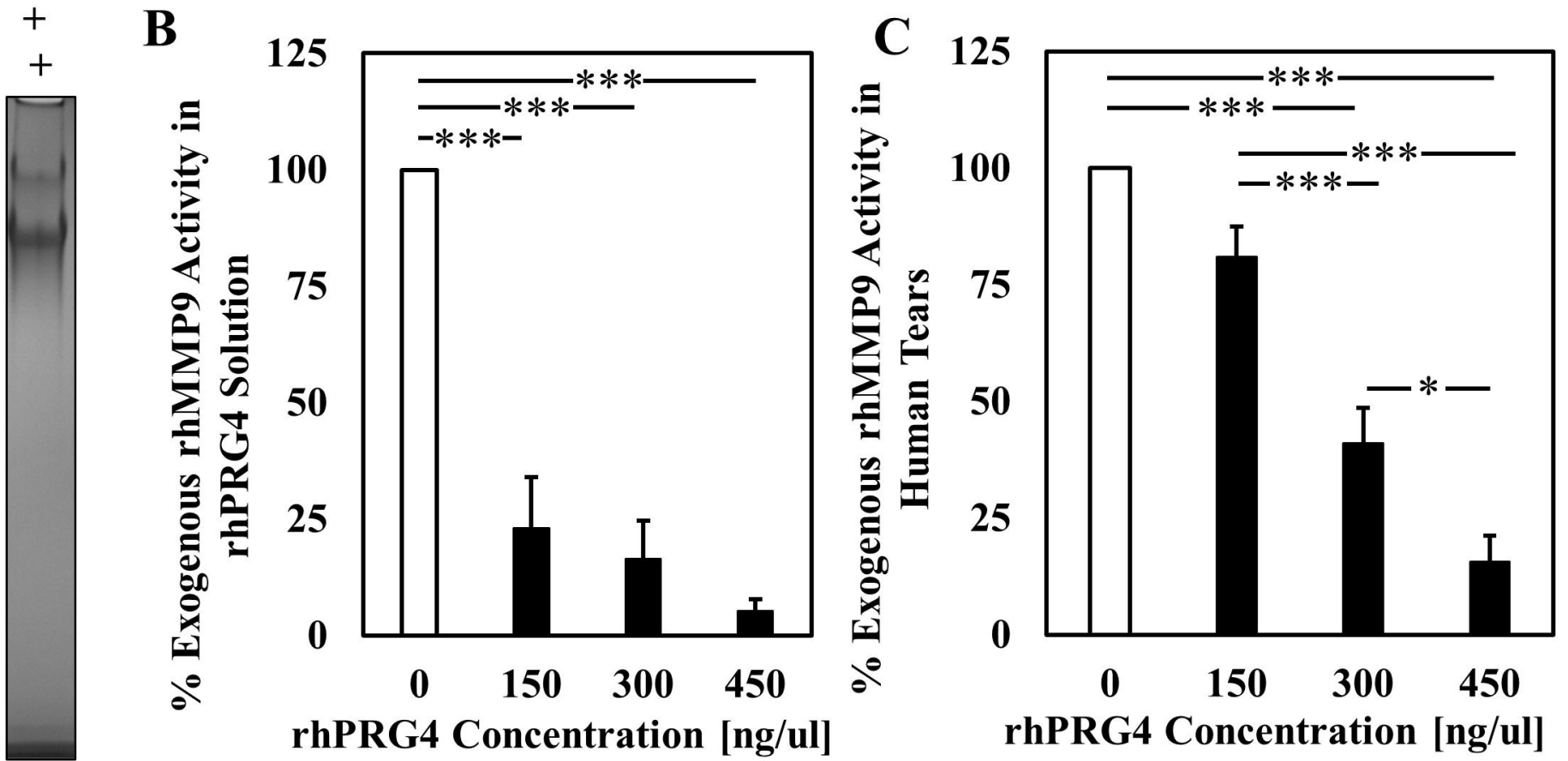


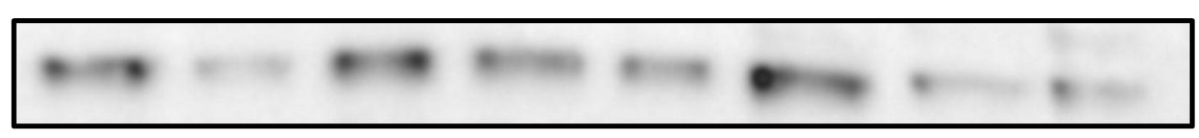

$\sum^{\frac{2}{5}}$ 0

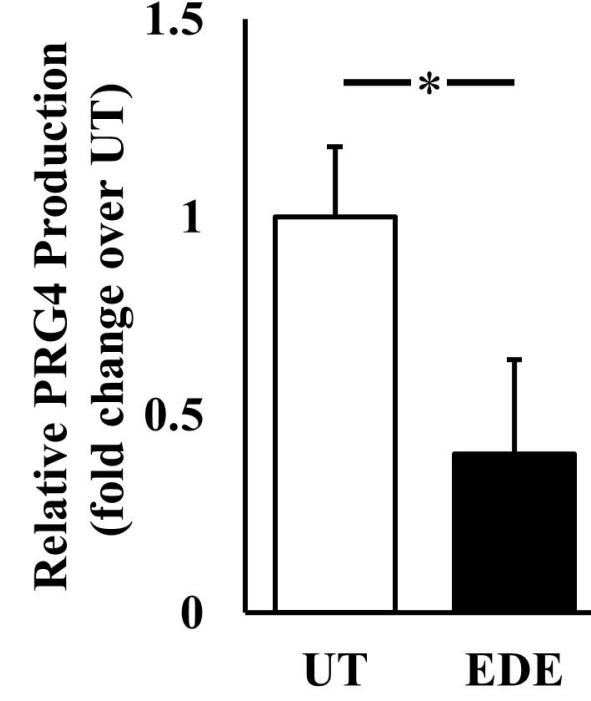

